\title{
Reducing the harmful effects of noise on the human environment. Sound insulation of industrial skeleton enclosures in the $10-40 \mathrm{kHz}$ frequency range
}

\author{
Witold Mikulski ${ }^{1}$ iD \\ Received: 28 August 2019 / Accepted: 4 October 2020 / Published online: 15 October 2020 \\ (C) The Author(s) 2020
}

\begin{abstract}
Purpose The purpose of the research is to work out a method for determining the sound insulation of acoustic enclosures for industrial sources emitting noise in the frequency range of $10-40 \mathrm{kHz}$ and apply the method to measure the sound insulation of acoustic enclosures build of different materials.

Methods The method is developed by appropriate adaptation of techniques applicable currently for sound frequencies of up to $10 \mathrm{kHz}$. The sound insulation of example enclosures is determined with the use of this newly developed method.

Results The research results indicate that enclosures (made of polycarbonate, plexiglass, sheet aluminium, sheet steel, plywood, and composite materials) enable reducing the sound pressure level in the environment for the frequency of $10 \mathrm{kHz}$ by $19-25 \mathrm{~dB}$ with the reduction increasing to $40-48 \mathrm{~dB}$ for the frequency of $40 \mathrm{~Hz}$. The sound insulation of acoustic enclosures with a soundabsorbing material inside reaches about $38 \mathrm{~dB}$ for the frequency of $10 \mathrm{kHz}$ and about $63 \mathrm{~dB}$ for the frequency of $40 \mathrm{kHz}$.

Conclusion Some pieces of equipment installed in the work environment are sources of noise emitted in the $10-40 \mathrm{kHz}$ frequency range with the intensity which can be high enough to be harmful to humans. The most effective technical reduction of the associated risks are acoustic enclosures for such noise sources. The sound pressure level reduction obtained after provision of an enclosure depends on its design (shape, size, material, and thickness of walls) and the noise source frequency spectrum. Realistically available noise reduction values may exceed $60 \mathrm{~dB}$.
\end{abstract}

Keywords Sound insulation · Acoustic enclosures $\cdot$ Soundproof enclosure $\cdot$ Ultrasound $\cdot$ Sound power level

\section{Introduction}

In their everyday life and work environment, humans are exposed to a plurality of harmful and uncomfortable factors. The noise is defined as sounds (acoustic vibrations) showing undesirable and/or harmful effect on humans or making it difficult to carry out specific activities. Such sounds reach humans as airborne stimuli. The fundamental parameter characterising quantitatively the intensity of sonic phenomena (including noise) in the frequency range $20-20,000 \mathrm{~Hz}$ is the Aweighted sound pressure level. Any noise characterised with values of that parameter exceeding $80 \mathrm{~dB}$ [1-7] can be the cause of permanent damage of hearing in a human being. In

Witold Mikulski

wimik@ ciop.pl

1 Central Institute For Labour Protection - National Research Institute, 16 Czerniakowska Str., Warsaw, Poland
Poland, the A-weighted sound pressure level of $85 \mathrm{~dB}$ is adopted as the so-called maximum admissible intensity (MAI) applicable in the context of the hearing protection [2, 3]. Any noise with the A-weighted sound pressure level falling in the range $55-75 \mathrm{~dB}$ can be detrimental to or prevent the exposed person from carrying out certain activities, including work-related ones (such as verbal communication) $[4,5]$. In Poland, admissible values of the A-weighted sound pressure level in the context of the employee's possibility to fulfilling their basic tasks depend on the nature of the work and are included in the range 55-75 $\mathrm{dB}$ [3]). In the everyday life environment, any noise with the A-weighted sound pressure level in the range $25-40 \mathrm{~dB}$ can make it difficult to have a rest, prevent from sleeping, etc. [4]. When the parameter used to determine intensity of sound is the A-weighted sound pressure level (and the quantities derived from it such as, for instance, the equivalent A-weighted sound pressure level or the Aweighted noise exposure level), the so-called audible sounds are being taken into account with frequencies falling into the 
range $20-20,000 \mathrm{~Hz}$ [3-5]. That limitation is adopted universally as it encompasses the vast majority of cases involving harmful effects of sounds on humans. However, such approach lacks completeness which could be reached only if all cases of undesirable or harmful effect of sound on humans are taken into account. Sounds with frequencies below $20 \mathrm{~Hz}$ (infrasounds) and sounds with frequencies higher than $20 \mathrm{kHz}$ (ultrasounds), though inaudible to the human ear, can be still unpleasant, bothersome, or even harmful [2-8]. In the human out-of-work environment, sound pressure levels of infrasounds and ultrasounds are small enough to be taken into account only in relatively rare cases, especially in the context of their harmful effects on humans [2-8]. However, ultrasounds present in the human work environment can be characterised with values of the sound pressure level (the parameter determining intensity of sound in this range of frequencies) so high that their effect on workers can be harmful [3-8] and must not be ignored. In Poland, when harmful and uncomfortable factors in the human work environment depending on frequency of involved sound vibrations are considered, the noise is categorised into three ranges, of which the first is called the infrasonic noise (the frequency range 1$20 \mathrm{~Hz}$ ), the second is referred to as the audible noise (the frequency range $20-20,000 \mathrm{~Hz}$ ), and the third is named the ultrasonic noise (the frequency range of about 10,000 $40,000 \mathrm{~Hz}$ ) [2, 3, 6-10]. In Poland, the latter noise category encompasses all $1 / 3$ octave frequency bands with mid-band frequencies falling into the range of $10-40 \mathrm{kHz}[2,3,6-14]$. In other countries, the $10-20 \mathrm{kHz}$ range is called the very high frequency range whereas the bracket of higher frequencies is referred to as the ultrasonic range [3-5].

The present paper focuses on the issue of occupational exposure of workers to the ultrasonic noise. In Poland, allowable values concerning this type of noise (admissible equivalent sound pressure level in $1 / 3$ octave band MAI) specified for workstations are $80 \mathrm{~dB}$ (in $1 / 3$ octave band with centre frequencies 10, 12.5 and $16 \mathrm{kHz}), 90 \mathrm{~dB}(20 \mathrm{kHz}), 105 \mathrm{~dB}$ $(25 \mathrm{kHz})$, and $110 \mathrm{~dB}(31.5$ and $40 \mathrm{kHz})[2,3]$. Admissible maximum sound pressure level MAI in Poland are by $20 \mathrm{~dB}$ larger than the equivalent value $[2,3]$. Lower MAI values apply to pregnant women and juveniles. In other countries, these values, although not identical, are similar [3, 4]. Evaluation of noise affecting humans in the work environment consists in determining whether the noise occurring at a specific workstation (measured values of parameters characterising noise) exceeds the levels quoted above (is acceptable/admissible) or not (is unacceptable/inadmissible).

The ultrasounds at workstations come from process ultrasonic sources (which generate ultrasounds intentionally to realise a technological process, e.g. heating an article) and from other devices in which the emission of ultrasounds is not an intended effect of the actually realised process [4, 6-9]. The process sources of the first type are the cause of significantly more intense ultrasonic noise compared to the other and are used in various technological processes, such as cleaning of materials (including mainly washing in liquids but also mechanical cleaning in, for instance, dental scale removers), erosion drilling, disintegration of materials (including production of powders in atomizers), welding of metals and non-metals, sterilisation (in medicine and food industry), blanking and piercing (including patterns in plastic films), cutting (in e.g. food industry), soldering, etc. [4, 6, 7, 9, 10]. The ultrasonic devices which use ultrasonic energy in the production process include: ultrasonic washers, ultrasonic welders (for plastic, metal and hardly wieldable materials), manual soldering units, ultrasonic crucibles, fabric treatment machines (jet machines, lace machines, and quilting machines), dental devices used for tartar removing (called scalers), ultrasonic guillotines, ultrasonic knives or ultrasonic curtains, ultrasonic erosion machines, and ultrasonic drills $[4,6,7,10]$. The ultrasonic noise emitted by the devices has, in the majority of cases, a narrowband spectrum corresponding to the frequency range in which the installed exciter of ultrasonic vibrations is operated [6-10]. For instance, exciters used in ultrasonic welders work typically with frequencies of 20,25,36, and $40 \mathrm{kHz}$. In many cases, ultrasonic noise level indicators (the equivalent sound pressure level in $1 / 3$ octave band and/or the admissible maximum sound pressure level) at workstations of operators of the devices exceed the above-quoted maximum admissible intensity levels MAI (in Poland, [2, 3]). Some of these devices can be operated in sealed (fully closed) sound-insulating enclosures [11] and then ultrasonic noise outside such enclosure is, in the majority of cases, very small and negligible from the point of view of its harmful effect on humans $[4,5]$. Therefore, fully sealed enclosures (especially those provided with an inner lining of sound absorbing material) turn out to be a very effective measure of ultrasonic sound reduction [11-22]. The parameter characterising acoustic effectiveness of an enclosure in scope of its ability to attenuate the sound penetrating through it is called "the sound insulation of acoustic enclosure" (or "the sound insulation of enclosure") in applicable standards and literature of the subject [11,15-21]. The value of the sound insulation of a given enclosure depends not only on its structure and materials of which it is constructed but also on the frequency spectrum of sound emitted by the enclosed noise source [11, 18-21]. Therefore, to design an effective sound-insulating enclosure for a specific device it is necessary to know sound insulation properties of enclosure walls and parameters characterising the noise emission from the source. Unfortunately, acoustic properties of sound-insulating enclosures (sound insulation of enclosure walls, but also the coefficient of absorption of materials used for enclosure inner linings) remains still a non-standardised quantity in the frequency range above $10 \mathrm{kHz}$ [11-28]. There is also no common agreement on methods for determining the parameters in this frequency range. Moreover, to date there exists no commonly 
accepted standard for evaluation of the parameter fundamental for determining the sound insulation of enclosure which is the sound power level of a source in the frequency range below $20 \mathrm{kHz}([9,10,22-26])$. That is a significant gap in the knowledge making impossible to carry out effective activities aimed at reduction of harmful effects of ultrasonic noise on humans. However, as measurements concerning such noise at workstations reveal that the admissible levels are exceeded, some manufacturers of ultrasonic equipment, despite the abovementioned incompleteness of the knowledge, strive to design, construct, and apply enclosures for their products on an ad hoc basis through trial and error. The effectiveness of these solutions is verified by taking measurements of noise at workstations. Although casual and accidental, such methods turn out to be effective in some cases. On the other hand, it must not be assumed that the acoustic effectiveness of a soundproof enclosure demonstrated for a specific noise source will be the same for another device, as different devices may (and in the majority of cases actually do) emit the ultrasonic noise of different frequencies which has an effect on effectiveness of attenuation of sound penetrating through the enclosures. It follows from the above that there is the need to initiate extensive research projects oriented at working out methods for determining, on one hand, emission of noise from devices, and on the other, properties of materials and enclosures (in the aspect of both sound-absorbing and sound-insulating properties) in the frequency range of $10-40 \mathrm{kHz}$. Research projects of that type have been already undertaken in such areas as the noise emissions from devices, sound absorbing properties of materials, and acoustic insulation performance of enclosures.

In case of enclosures it is also possible to adopt another approach. One may develop a method for determining the sound insulation of enclosure and other sound insulation properties for typical soundproof enclosures (with walls made of various materials with different thickness) in the whole frequency range of interest by using a standard broad-band sound source. Results of such tests would enable determining the effect of the type and thickness of materials used to construct the enclosures on their sound-insulating properties. Given the test data and gaining knowledge of the emission from an ultrasonic noise source or immission of ultrasonic noise at a workstation, it would be possible to select the most suitable sound-insulating enclosure. Such approach was adopted in the study reported in the present paper.

When determining the sound insulation of soundproof enclosures, the typical design solution was selected for examination, namely the skeleton structure with walls made of various materials such as sheet steel or aluminium, polycarbonate or plexiglass boards, or plywood. The methods for determining the sound power level of source without and with enclosure and the sound insulation of enclosure were developed with the specificity of sound radiation and propagation in the frequency range above $10 \mathrm{kHz}$ taken into account (including, in particular, high directivity of sound radiation emitted by such sources and the significant effect of damping highfrequency sounds in air [9-12, 25, 29, 30]).

The article presents the method for determining the sound insulation of enclosures for a noise source emitting sound energy in the frequency range of $10-40 \mathrm{kHz}$ (as a result of the author's previous research [30]). The method is based on measurements of the insertion loss when the sound power level of a reference source is determined [9, 10, 24, 25, 30], the quantity being called "the sound power insulation" in [18, $19,30]$ and determined in $1 / 3$-octave frequency bands with centre frequencies of $10,12.5,16,20,25,31.5$, and $40 \mathrm{kHz}$.

Moreover, results are given of tests on the sound insulation of skeleton enclosures made of different materials with different thickness of acoustic enclosure walls and further, with and without some sound-absorbing material inside the enclosure $[11-13,30]$. The objective of the tests was to specify the usefulness of various materials for walls of sound-absorbing and insulating skeleton enclosures for technological ultrasonic noise sources $[14,30]$.

The proposed methods for determining the sound power level for a noise source in the frequency range from $20 \mathrm{kHz}$ to $40 \mathrm{kHz}$ and the sound insulation of enclosures in the frequency range from $10 \mathrm{kHz}$ to $40 \mathrm{kHz}$ are novel. Results of testing skeleton enclosures walls of which are made of various materials with different thickness are also new as to date, acoustic properties of enclosures in the frequency range above $10 \mathrm{kHz}$ were not determined (except for results concerning enclosures made of plywood which were published by the present author in [30]).

\section{Materials and methods}

\section{Scope of research - Test samples}

The subject-matter of the study was:

I. Comparing the sound insulation of skeleton enclosures with walls made of various materials (without soundabsorbing materials used inside the enclosure):

- single-layer polycarbonates PC, wall thickness of $5 \mathrm{~mm}$ (for short, abbreviated PC5);

- single-layer poly(methyl methacrylate) PMMA, wall thickness of $5 \mathrm{~mm}$ (abbreviated PMMA5);

- $\quad$ single-layer sheet steel, wall thickness of $2 \mathrm{~mm}$ (abbreviated STEEL2);

- single-layer sheet aluminium, wall thickness of $2 \mathrm{~mm}$ (abbreviated $A L 2$ );

- single-layer plywood, wall thickness of $6 \mathrm{~mm}$ (abbreviated $P W 6$ ); 
- three-layer composite (sheet aluminium $0.3 \mathrm{~mm}+$ polyethylene $3.4 \mathrm{~mm}+$ sheet aluminium $0.3 \mathrm{~mm}$ ) (abbreviated ALPO4).

II. Comparing the sound insulation of skeleton enclosures with walls made of aluminium and plywood of different thickness:

- $\quad$ single-layer sheet aluminium, wall thickness of $4 \mathrm{~mm}$ and $2 \mathrm{~mm}$ (abbreviated $A L 4$ and $A L 2$ );

- $\quad$ single-layer plywood, wall thickness of $12 \mathrm{~mm}$ and $6 \mathrm{~mm}$ (abbreviated $P W 12$ and $P W 6$ ).

III. Comparing the sound insulation of skeleton enclosures with walls made of three materials, enclosures with and without inner lining of $15 \mathrm{~mm}$ polyurethane foam:

- single-layer sheet aluminium, wall thickness of $2 \mathrm{~mm}$, without and with $15 \mathrm{~mm}$ foam lining (abbreviated AL2 and $A L 2+F O A M$, respectively);

- $\quad$ single-layer plywood, wall thickness of $6 \mathrm{~mm}$, without and with $15 \mathrm{~mm}$ foam lining (abbreviated $P W 6$ and $P W 6+F O A M$, respectively);

- three-layer composite (sheet aluminium $0.3 \mathrm{~mm}+$ polyethylene $3.4 \mathrm{~mm}+$ sheet aluminium $0.3 \mathrm{~mm}$ ), without and with $15 \mathrm{~mm}$ foam lining (abbreviated ALPO4 and ALPO4 + FOAM, respectively).

\section{The test method}

The objective of the tests was to determine the effect of different materials used to construct acoustic enclosures and the impact of acoustic enclosure with lining of sound absorbing material on the sound reduction effectiveness of enclosures for noise sources emitting the sound in the frequency range of $10-40 \mathrm{kHz}$.

The test method involved comparing results of determination of the sound power insulation [11, 16-18, 21, 30] of a skeleton acoustic enclosure with walls made of six different materials, with and without lining of sound absorbing material.

To date, the sound insulation of acoustic enclosures for noise sources was determined with the use of parameters such as the sound power or pressure insulation in the frequency range below $10 \mathrm{kHz}[18,19]$. The method for determining these quantities within the frequency range of $10-40 \mathrm{kHz}$ is provided below. The rationale behind the need to work out such method was that in this frequency range, the value of the sound pressure insulation depends, to a large extent, on directional properties of the sound source. Therefore, the parameter that characterises the acoustic enclosure sound insulating properties more appropriately is the sound power insulation of enclosure (the use of the word "power" means that the sound insulation is calculated from the sound power level, the term being consistent with the commonly adopted standards EN ISO 115462:2009 and EN ISO 15667:2000 [18, 19]). The sound power insulation, on the analogy of $[2,3,6-14,16,18$, $19,21,28,30]$, is determined in $1 / 3$-octave frequency bands with centre frequencies $f i(10,12.5,16,20,25$, 31.5 , and $40 \mathrm{kHz}$ ) according to the following formula:

$D_{W, f i}=L_{W, \text { without }, f i}-L_{W, \text { with }, f i}$

where:

$L_{W, \text { without }, f i}$

$L_{W, \text { with }, f}(\mathrm{~dB})$

the sound power level, in 1/3-octave frequency band with the centre frequency $f i$, for a laboratory sound source without acoustic enclosure and provided with the acoustic enclosure, respectively.

The source sound power level, as for the frequency below $10 \mathrm{kHz}$ [22-24, 26] or below $20 \mathrm{kHz}$ [25] (both inside and without the enclosure), is calculated using the following formula:

$L_{W, f i}=\left\langle L_{p, f i}^{\prime}\right\rangle-K_{\mathrm{bgn}, f i}-K_{\mathrm{env}, f i}+10 \log _{10}(\{S\}) \mathrm{dB}+K_{\mathrm{air}, f i}$

where:

$\left\langle L_{p, f i}^{\prime}\right\rangle \quad$ the average sound pressure level on the

(dB) measurement surface encompassing the laboratory sound source (in 1/3-octave frequency band with the centre frequency $f i$,

$K_{\mathrm{bgn}, f i} \quad$ the correction taking into account the background (dB) noise during the measurements (in 1/3-octave frequency band with the centre frequency $f i$ ),

$K_{\text {env, } f i}$ the environmental correction in 1/3-octave fre-

(dB) quency band with the centre frequency $f i$,

$K_{\text {air, } f i}$ the air correction [9-12, 25, 29, 30] in 1/3-octave

(dB) frequency band with the centre frequency $f i$,

$S\left(\mathrm{~m}^{2}\right) \quad$ the measurement surface area.

The average sound pressure level on the measurement surface is calculated in 1/3-octave frequency bands with centre frequencies $f i(10,12.5,16,20,25,31.5$, and $40 \mathrm{kHz})$ according to the formula

$\left\langle L_{p, f i}^{\prime}\right\rangle=10 \log _{10}\left(\frac{1}{n} \sum_{j=1}^{n} 10^{0.1 \cdot L_{p, f i, j}}\right) \mathrm{dB}$

where:

$n \quad$ the number of measurement points,

$L_{p, f i, j} \quad$ the sound pressure level on the measurement

(dB) surface at point number $j$ (Fig. 1), in 1/3-octave frequency band with the centre frequency $f i$. 

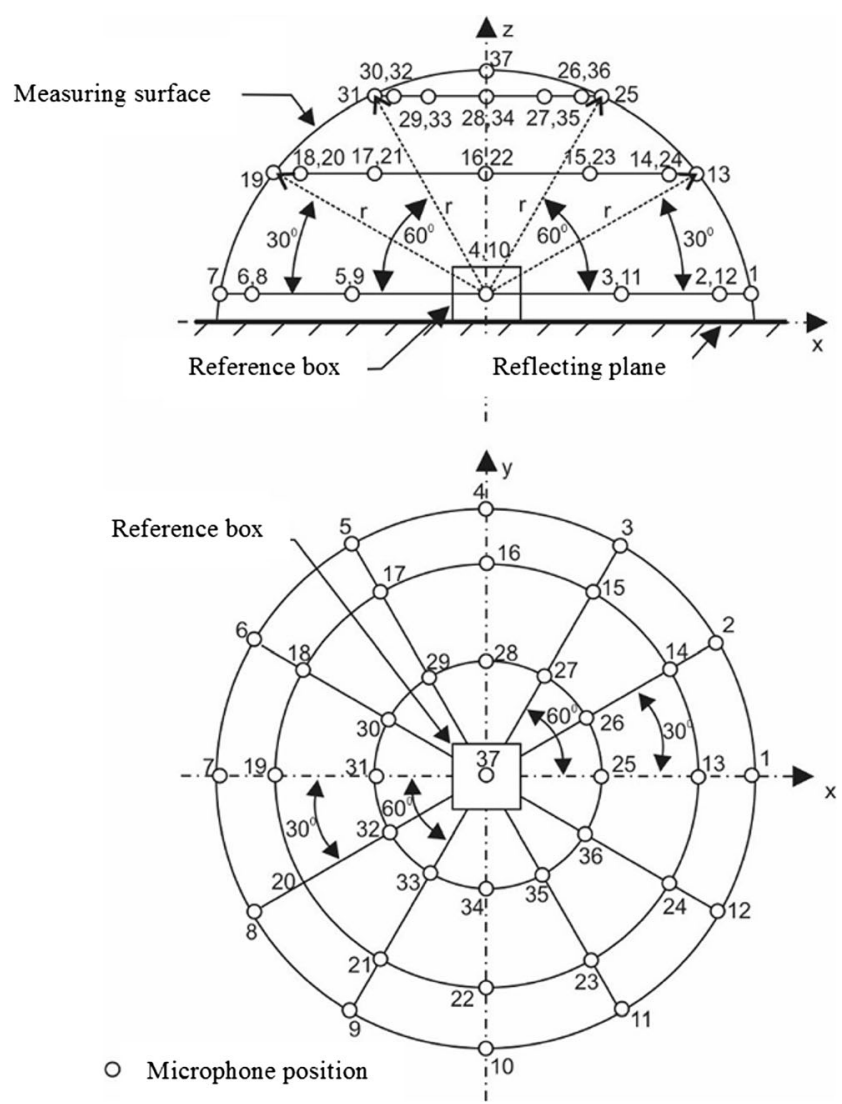

Fig. 1 Distribution of 37 measurement points on a hemispherical measuring surface used for the determination of sound insulation properties of enclosures $[9,10,30]$

The correction taking account of the background noise $K_{\mathrm{bgn}, f i}$ is calculated in $1 / 3$-octave frequency bands with centre frequencies $f i(10,12.5,16,20,25,31.5$, and $40 \mathrm{kHz})$ with the use of the following formula:

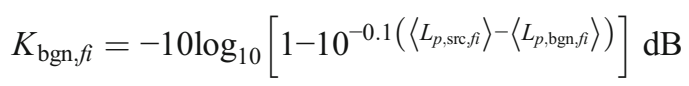

where:

$\left\langle L_{p, \text { src }, f i}\right\rangle \quad$ the average value of the sound pressure level, in (dB) 1/3-octave frequency band with centre frequency $f i$, on the measurement surface when the laboratory sound source is active, calculated from the formula of Eq. (3),

$\left\langle L_{p, \text { bgn, } f i}\right\rangle \quad$ the average value of the sound pressure level, in (dB) 1/3-octave frequency band with centre frequency $f i$, on the measurement surface when the laboratory source is inactive, calculated from the formula of Eq. (3).

The background noise correction $K_{\mathrm{bgn}, f i}$ must not exceed $3 \mathrm{~dB}$.

The environmental correction $K_{\mathrm{env}, f i}$ in rooms with a hemispherical measurement surface is calculated in $1 / 3$-octave

frequency bands with centre frequencies $f i(10,12.5,16,20$, $25,31.5$, and $40 \mathrm{kHz}$ ) according to the formula

$K_{\mathrm{env}, f i}=10 \log _{10}\left(1+4 \frac{S}{A_{f i}}\right) \mathrm{dB}$

where:

$S\left(\mathrm{~m}^{2}\right) \quad$ the measurement surface area (for a hemispherical measurement surface with radius $r, S=2 \pi r^{2}$ ),

$A_{f i}$ the sound absorption of the room, in 1/3-octave fre$\left(\mathrm{m}^{2}\right) \quad$ quency band with centre frequency $f$,

$V\left(\mathrm{~m}^{3}\right)$ the test room volume.

The environmental correction $K_{\text {env }, f}$ for the assumed hemispherical measurement surface in the room where tests were conducted is presented in Table 1.

Calculations concerning the sound insulation of enclosures do not take into account the correction $K_{\text {env }, f i}$ (it will be eliminated in the course of calculations). That does not mean that this value is of no importance. Small values of the environmental correction serve as an evidence that measurements were conducted in a quasi-free field, and thus in accordance with the basic assumption of the method. Therefore, the value of this specific correction should not exceed $4 \mathrm{~dB}\left(K_{\mathrm{env}, f i} \leq\right.$ $4 \mathrm{~dB}$, similarly as provided in EN ISO 9295 [25]).

The air correction $K_{\mathrm{air}, f i}$ at the distance of $1 \mathrm{~m}$, i.e. $K_{\mathrm{air}, 1 \mathrm{~m}, f i}$, was estimated with the use of the extrapolation method on the basis of data from PN-EN ISO 9295 [25].

Because determination of the sound power insulation for an acoustic enclosure consists in calculation of differences between sound power levels on the same measurement surface in the same room, values of the air correction $K_{\mathrm{air}, f i}$ and the environmental correction $K_{\text {env, } f i}$ do not affect the result of the sound insulation determination. Therefore, the sound insulation formula of Eq. (1) can be transformed into the following form:

$$
\begin{aligned}
& D_{W, f i}=L_{W, \text { without }, f i}-L_{W, \text { with }, f i}= \\
& =\left\langle L_{p, \text { without } f f i}^{\prime}\right\rangle-K_{\text {bgn, without }, f i}-K_{\text {env }, f i}+10 \log (\{S\}) \mathrm{dB}+K_{\text {air } f i} \\
& -\left(\left\langle L_{p, \text { with }, f i}^{\prime}\right\rangle-K_{\text {bgn,with }, f i}-K_{\text {env }, f i}+10 \log (\{S\}) \mathrm{dB}+K_{\text {air }, f i}\right) \\
& =\left\langle L_{p, \text { without }, f i}\right\rangle-K_{\text {bgn, without }, f i}-\left(\left\langle L_{p, \text { with }, f i}^{\prime}\right\rangle-K_{\text {bgn,with }, f i}\right) \\
& =\left\langle L_{p, \text { without }, f i}^{\prime}\right\rangle-\left\langle L_{p, \text { with }, f i}^{\prime}\right\rangle+K_{\text {bgn, with }, f i}
\end{aligned}
$$

where:

$L_{W \text {,without, } f i}$ and $L_{W, \text { with, } f i}(\mathrm{~dB})$

$L_{p, \text { without }, f i}^{\prime}$ and $L$ 'p, with, $f i(\mathrm{~dB})$ the sound power levels, in $1 / 3$-octave frequency band with the centre frequency $f i$, for a laboratory sound source, without acoustic enclosure and provided with the enclosure, respectively, the average sound pressure levels on the surface encompassing the laboratory sound source, in 1/3-octave 
Table 1 The environmental correction $K_{\mathrm{env}, f}$ and the air correction $K_{\text {air } r f}$ for hemispherical measurement surface with radius $r=1 \mathrm{~m}$ in the room where measurements were taken [9-12, $25,29,30]$

\begin{tabular}{lccccccc}
\hline Frequency $(\mathrm{kHz})$ & 10 & 12.5 & 16 & 20 & 25 & 31.5 & 40 \\
\hline$K_{\text {env }, f i}($ for $r=1 \mathrm{~m})(\mathrm{dB})$ & 0.31 & 0.27 & 0.24 & 0.21 & 0.20 & 0.15 & 0.14 \\
$K_{\text {air, } 1 \mathrm{~m}, f i}($ for humidity $50 \%$ & 0.15 & 0.22 & 0.34 & 0.50 & 0.74 & 1.11 & 1.68 \\
$\quad$ and temperature $\left.22^{\circ} \mathrm{C}\right)(\mathrm{dB})$ & & & & & & & \\
\hline
\end{tabular}

frequency band with the centre frequency $f i$, without and with acoustic enclosure, respectively, calculated from the formula of Eq. (3),

$K_{\text {bgn, without } f i}$ and

$K_{\text {bgn,with, } f i}(\mathrm{~dB})$

$K_{\text {env }, f i}(\mathrm{~dB})$

$S\left(\mathrm{~m}^{2}\right)$ corrections for the background noise during the measurements, in 1/3-octave frequency band with the centre frequency $f i$, for the laboratory source without and with acoustic enclosure, respectively, calculated from the formula of Eq. (4) (in any case, $K_{\text {bgn, with, } f i}$ must not exceed $3 \mathrm{~dB}$, and since the difference of the average sound pressure level on the measurement surface during measurements concerning the source without acoustic enclosure in the tested room and the measurements of the background noise in the considered frequency bands exceeded $15 \mathrm{~dB}$, $K_{\text {bgn, without }, f i}$ can be omitted because it does not affect the final result), the environmental correction in 1/3octave frequency band with the centre frequency $f i$ (can be omitted because it does not affect the result but in any case, $K_{\text {env, } f i}$ must not exceed $4 \mathrm{~dB}$ ), the measurement surface area (which does not affect the final result).
The tests were conducted in a room with high sound absorption (semi-anechoic room) and a highly reflective floor (Fig. 1). The tests were conducted above the reflective surface.

The number of measurement points at which the sound pressure level on the measurement surface was measured was assumed to be 37 (in accordance with the requirements of EN ISO 3744 [24], whereas according to EN ISO 9295 [25], for the technical method, the number of measurement points must be greater than the maximum difference of sound pressure level values on the measurement surface. From the present author's own research concerning determination of the minimum number of measurement points for the purpose of evaluation of the sound power level for ultrasonic noise sources $[9,10]$, the minimum number of measurement points is 20. In cases when the condition established in EN ISO 3744
[24] is not met, the number of measurement points should be increased. The set of 37 measurement points can be distributed on the hemispherical measurement surface every $30^{\circ}$ of the plane angle, both in the horizontal and vertical plane (Fig. 1).

In Fig. 2, results of measurement of maximum differences in the sound pressure level on the measuring surface $\Delta L_{p, \max }$ are presented. For the entire frequency range, the maximum difference in the sound pressure levels on the measuring surface $\Delta L_{p \text {,max }}$ did not exceed $20 \mathrm{~dB}$ and was significantly lower than the allowable value of $37 \mathrm{~dB}$. It stems from this that the number of 37 measurement points adopted for the tests is representative and has been selected in a correct manner.

The laboratory equipment used for the tests carried out in the frequency range of 10-40 kHz included (Fig. 3):

- in the sound generating portion: noise generator $8-50 \mathrm{kHz}$ PULSE type 3560C with PULSE multi-analyser (Brüel \& Kjær), RX 797 power amplifier (Yamaha), and self-made column loudspeaker in the form of a truncated squarebased pyramid with 4 R2904-7000 loudspeakers (ScanSpeak);

- in the sound-measuring portion: $1 / 4$-in. microphone with type 4944A preamplifier, input/output module 3110 type 3560C, and Data-Software system for PULSE Types LabShop type 7700 (all from Brüel \& Kjær).

\section{Test results}

\section{The sound power insulation of skeleton acoustic enclosures with walls made of different materials (without sound-absorbing materials inside)}

In Fig. 4 and in Table 2, results of determination of the sound power insulation are given for skeleton enclosures (without any lining on their inner surface) with walls made of PMMA5, PC5, STEEL2, AL2, PW6, and ALPO4.

The values of the sound power insulation of skeleton enclosures with walls made of these different materials were included in the range from $18.8-27.1 \mathrm{~dB}$ (for the frequency of $10 \mathrm{kHz}$ ) to $40.2-47.5 \mathrm{~dB}$ (for frequency of $40 \mathrm{kHz}$ ), as shown in Fig. 4. 
Fig. 2 The maximum difference in the sound pressure levels on the measuring surface $\Delta L_{p, \max }$ for the laboratory source without acoustic enclosure, with acoustic enclosure with walls made of ALPO4, and with enclosure with walls made of ALPO4 lining of foam ALPO4 + FOAM

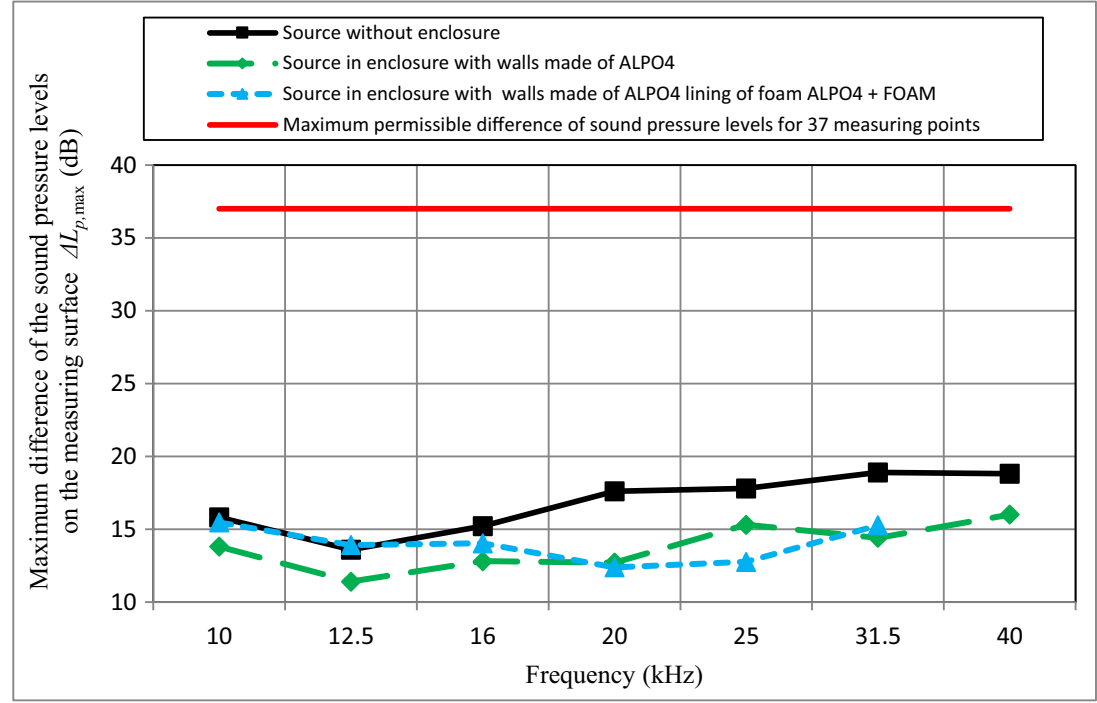

In the frequency range under consideration, a monotonic increase of the sound power insulation $D_{W}$ value with increasing sound frequency was observed. For enclosure with walls made of PMMA5, PC5, STEEL2, and AL2, the sound
Fig. 3 Laboratory equipment used for measurements in the frequency range $10-40 \mathrm{kHz}$ : a equipment (described above in the text), $\mathbf{b}$ the measured sound power level (a)

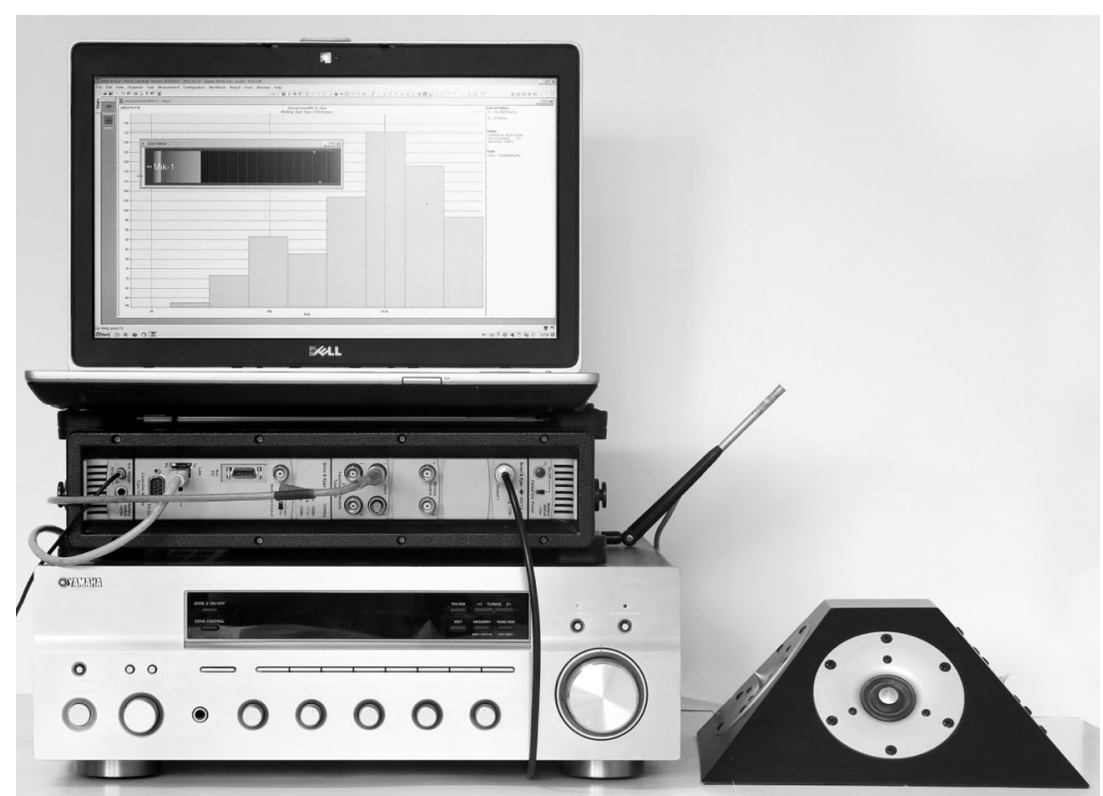

(b)

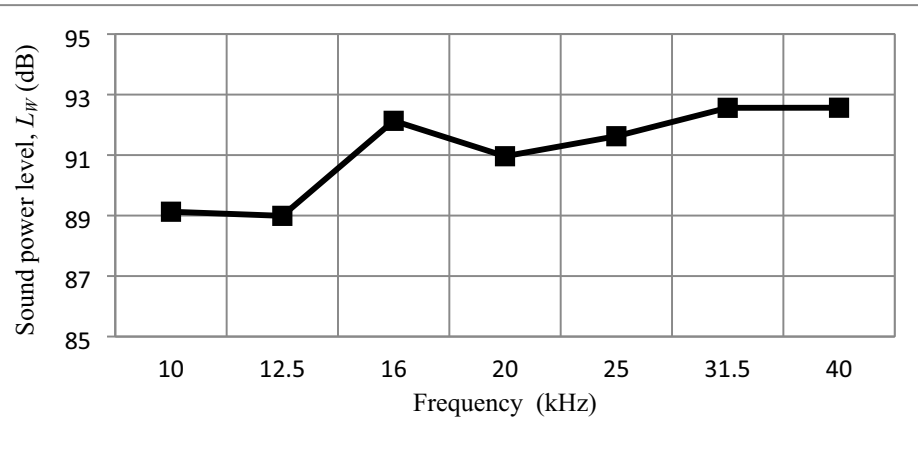


Table 2 The effect of increasing sound frequency on the sound power insulation $\Delta D_{W}$ of skeleton acoustic enclosures with walls made of different materials

Material used for enclosure walls

Average increase of sound power insulation $\Delta D_{W}$ for the frequency increase $(\mathrm{dB})$

by an octave by $1 / 3$ of an octave

PMMA5 - single-layer PMMA poly(methyl methacrylate), wall thickness $5 \mathrm{~mm}$

$\begin{array}{rr}12.5 & 4.0 \\ 12.8 & 3.5 \\ 12.3 & 3.4 \\ 12.1 & 3.5 \\ 9.6 & 2.8 \\ 10.3 & 3.2\end{array}$

power insulation $D_{W}$ increased by about $12.5 \mathrm{~dB}$, and for walls made of PW6 and ALPO4 by about $10 \mathrm{~dB}$ for doubled sound frequency, i.e. per an octave (Table 2). The average increase of the sound power insulation $D_{W}$ corresponding to the sound frequency increased by $2^{1 / 3}$ (per $1 / 3$ of an octave) for acoustic enclosure walls made of PMMA5, PC5, STEEL2, and AL2 was about $3.5 \mathrm{~dB}$, compared to about $3 \mathrm{~dB}$ for enclosures with walls made of PW6 and ALPO4.

The highest sound power insulation $D_{W}$ was observed for the acoustic enclosure with steel walls of $2 \mathrm{~mm}$ thick STEEL2 (27.1-47.5 dB in the frequency range of $10-40 \mathrm{kHz}$, Fig. 4). The lowest sound power insulation $D_{W}$ was measured for the acoustic enclosure with walls made of ALPO4 composite (sheet aluminium $0.3 \mathrm{~mm}+$ polyethylene $3.4 \mathrm{~mm}+$ sheet aluminium $0.3 \mathrm{~mm}$ ) and amounted to $20.7-40.2 \mathrm{~dB}$ in the frequency range of $10-40 \mathrm{kHz}$. In the frequency bands centred at of 10 and $12.5 \mathrm{kHz}$, a slightly lower sound power insulation $D_{W}$ was observed for the acoustic enclosure with walls made of PMMA5, where the value of $18.8 \mathrm{~dB}$ was measured for the frequency of $10 \mathrm{kHz}$.

The maximum differences in the sound power insulation $D_{W}$ for the tested enclosure were included within the bracket of 5.1$8.4 \mathrm{~dB}$ (for each frequency within the range of $10-40 \mathrm{kHz}$ ). This means that for an ultrasonic sound source emitting the sound energy in a narrow frequency band (tonally), the sound power insulation of an acoustic skeleton enclosure may vary by from about 5 to about $8 \mathrm{~dB}$ depending on the material used for the walls. Therefore, the sound pressure level in the vicinity of enclosures with walls of different materials will be by 5 to $8 \mathrm{~dB}$ higher or lower, depending on the materials used for the enclosure walls. The difference, not large as it may seem, can be nevertheless considered important because it can result in a reduction or an increase of the human exposure to noise by $5-8 \mathrm{~dB}$.

The above conclusions concern enclosures without any sound-absorbing material used inside, in particular, on enclosure internal walls.
Fig. 4 The sound power insulation $D_{W}$ of skeleton acoustic enclosures with walls made of different materials and without any sound-absorbing materials inside (results for PW6 were published in [30])

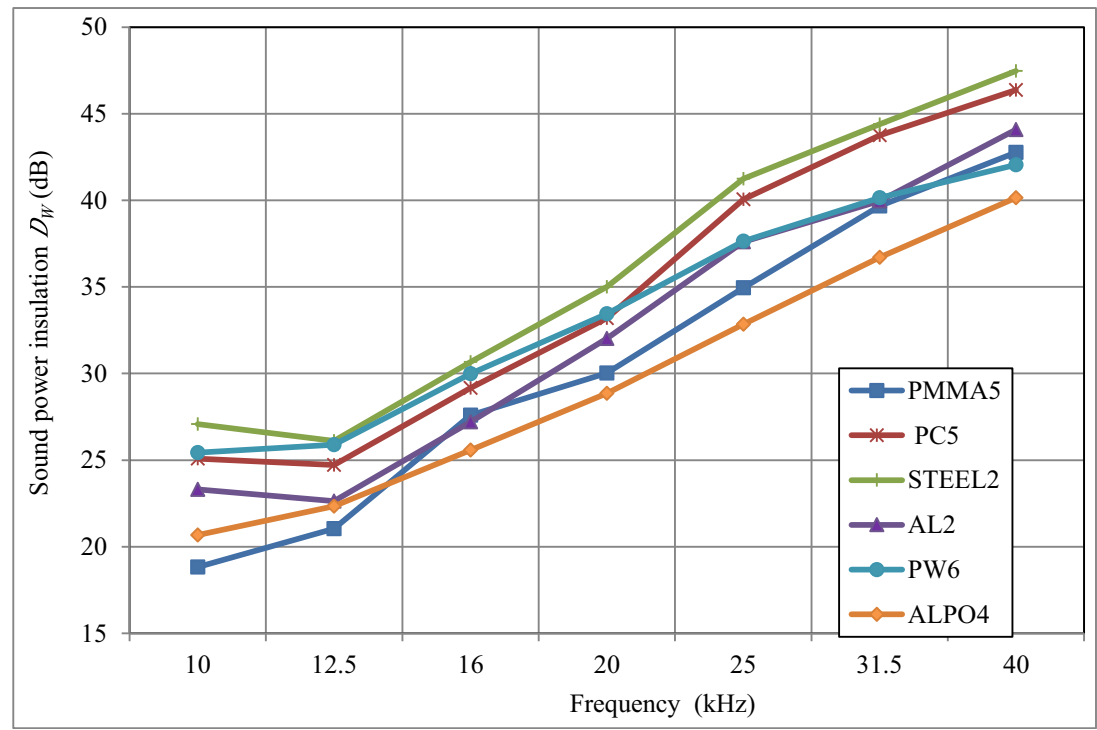


Fig. 5 The sound power insulation $D_{W}$ for skeleton enclosures with walls made of single-layer $2 \mathrm{~mm}$ and $4 \mathrm{~mm}$ sheet aluminium, with average values compared to those obtained for enclosure of single-layer $2 \mathrm{~mm}$ sheet steel

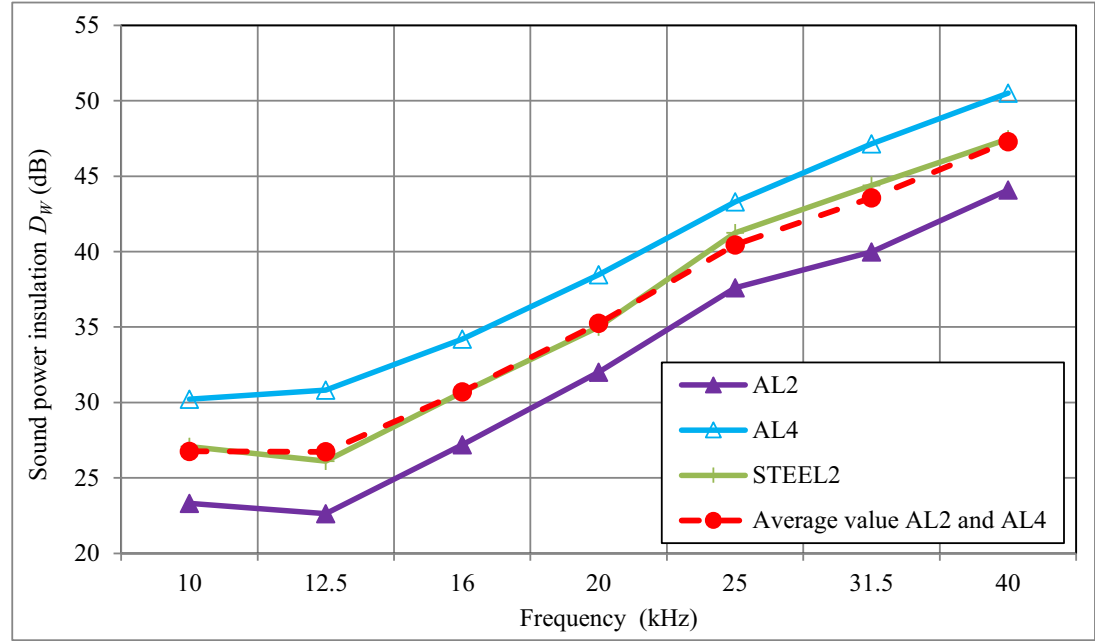

\section{The sound power insulation of skeleton acoustic enclosures with walls made of aluminium and plywood of various thickness (without sound- absorbing materials inside)}

In Fig. 5, the sound power insulation $D_{W}$ of skeleton acoustic enclosures made of sheet aluminium with $2 \mathrm{~mm}$ and $4 \mathrm{~mm}$ thick walls (AL2 and AL4) is plotted. For the sake of comparison, results of the same test with the skeleton acoustic enclosure made of steel with $2 \mathrm{~mm}$ thick walls (STEEL2) are also provided.

The sound power insulation of the skeleton acoustic enclosure made of $2 \mathrm{~mm}$ aluminium AL2 is lower than this measured for the acoustic enclosure made of steel STEEL2 by about $3.6 \mathrm{~dB}(3.0-4.4 \mathrm{~dB}$ in the frequency range under consideration; Fig. 5). The arithmetic average value of the sound power insulation $D_{W}$ value for the enclosure made of $2 \mathrm{~mm}$ AL2 and $4 \mathrm{~mm}$ AL4 aluminium (the so-called predicted value for the acoustic enclosure with $3 \mathrm{~mm}$ thick walls) is almost identical to the sound power insulation $D_{W}$ of the enclosure made of $2 \mathrm{~mm}$ steel STEEL2. This proves that in the frequency range of 10-40 kHz, to obtain similar values of the sound power insulation $D_{W}$ for the enclosure made of steel and aluminium, the walls of the latter should be twice as thick which, however, would still make the aluminium enclosures about half as light as the steel ones (the density of aluminium is $2720 \mathrm{~kg} / \mathrm{m}^{3}$ compared to $7500-7900 \mathrm{~kg} /$ $\mathrm{m}^{3}$ for various steel grades).

In the frequency range of $10-40 \mathrm{kHz}$, the sound power insulation $D_{W}$ of the skeleton acoustic enclosure made of sheet aluminium with $4 \mathrm{~mm}$ thick walls (AL4) is higher than the sound insulation of the skeleton acoustic enclosure made of sheet aluminium with $2 \mathrm{~mm}$ thick walls (AL2) by $6.8 \mathrm{~dB}$ on average (5.7-8.2 dB; Fig. 6). From this it follows that for doubled thickness of aluminium walls (and the corresponding two-fold increase of the enclosure mass), the increase of the sound power insulation $D_{W}$ by about $7 \mathrm{~dB}$ is observed (Fig. 6). Analogously, two-fold increase of plywood walls thickness (doubled acoustic enclosure mass) results in the increase of the sound power insulation $D_{W}$ by about $4.9 \mathrm{~dB}$ (Fig. 6). Most
Fig. 6 The difference in the sound power insulation $\Delta D_{W}$ for walls of skeleton enclosures made of $4 \mathrm{~mm}$ and $2 \mathrm{~mm}$ thick aluminium and for walls made of $12 \mathrm{~mm}$ and $6 \mathrm{~mm}$ thick plywood (results of sound power insulation for the skeleton enclosure made of PW6 and PW12 were published in [30])

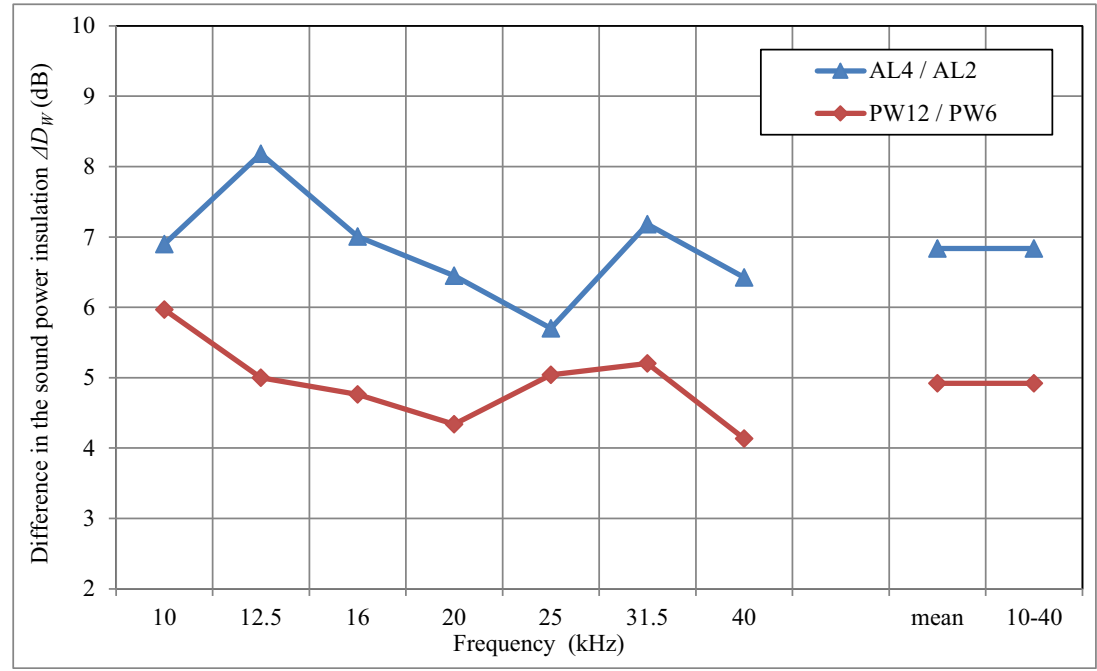


Fig. 7 The sound power insulation $D_{W}$ of skeleton acoustic enclosures with walls made of aluminium AL2, plywood PW6, and composite ALPO4

(sheet aluminium $0.3 \mathrm{~mm}+$ polyethylene $3.4 \mathrm{~mm}+$ sheet aluminium $0.3 \mathrm{~mm}$ ) with and without $15 \mathrm{~mm}$ foam

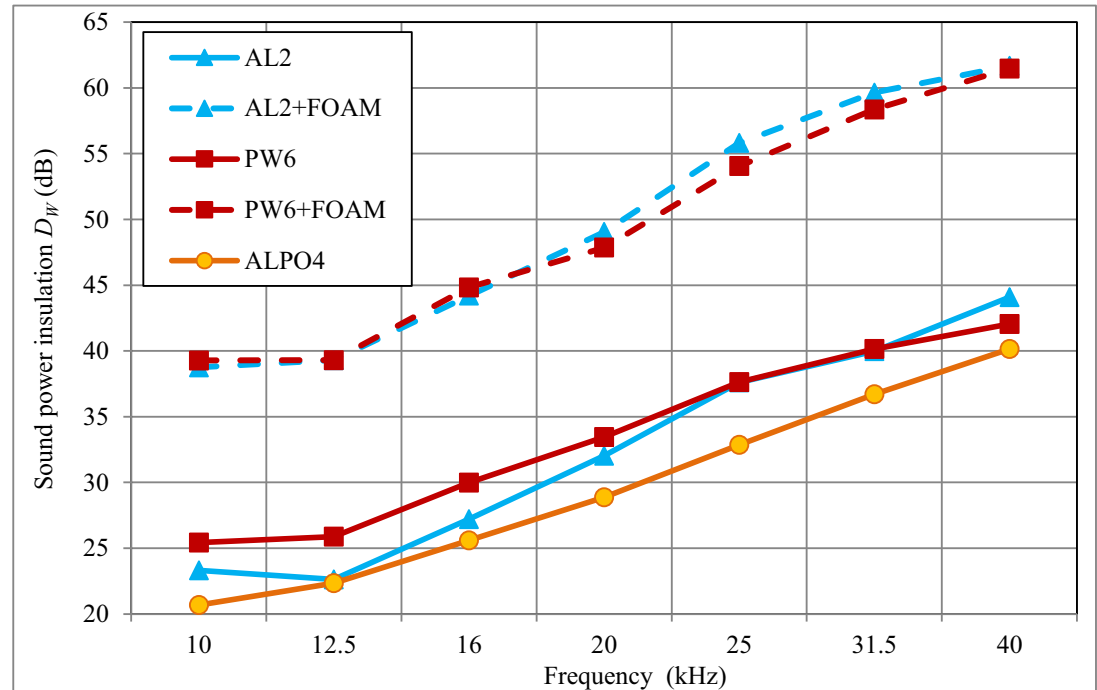

probably, the larger impact of the increase of aluminium walls thickness compared to the increase of plywood walls thickness on the acoustic enclosure sound power insulation $D_{W}$ is caused by, apart from the mass (the density of aluminium and wood is $2720 \mathrm{~kg} / \mathrm{m}^{3}$ and about $600 \mathrm{~kg} / \mathrm{m}^{3}$, respectively), the higher rigidity of thicker aluminium walls $(4 \mathrm{~mm})$.

The conclusions from the above analysis apply also to acoustic enclosures without the sound-absorbing material used inside.

\section{The sound power insulation of skeleton acoustic enclosures with walls made of different materials with sound-absorbing materials on the inside walls}

In Figs. 7 and 8, results of determination of the sound power insulation $D_{W}$ are given for skeleton acoustic enclosures with $2 \mathrm{~mm}$ thick aluminium walls (AL2), $6 \mathrm{~mm}$ thick plywood walls (PW6), and $4 \mathrm{~mm}$ thick composite walls (ALPO4) lined inside with $15 \mathrm{~mm}$ thick polyurethane foam.
The maximum difference in the sound power insulation $D_{W}$ for skeleton enclosures with walls made of $2 \mathrm{~mm}$ aluminium (AL2), $6 \mathrm{~mm}$ plywood (PW6), and $4 \mathrm{~mm}$ composite (ALPO4), all of which were lined with a sound-absorbing material (15 $\mathrm{mm}$ polyurethane foam) inside, depending on the frequency (in the range of 10$40 \mathrm{kHz}$ ), remained within the range of $0.79-2.44 \mathrm{~dB}$ (1.7 dB on average; Fig. 7). Taking into consideration that the sound power insulation $D_{W}$ of such enclosures (with sound-absorbing foam inside) was included within the range of $38.5-64 \mathrm{~dB}$, it can be stated that the use of inner foam lining masked the effect of various sound insulation properties of acoustic enclosures (without any sound-absorbing material inside) resulting from different materials they were made of.

The average increase of the sound insulation of acoustic enclosures in the frequency range of 10 $40 \mathrm{kHz}$ after application of a $15 \mathrm{~mm}$ foam lining on their inside walls (Fig. 8) was as follows: $17.4 \mathrm{~dB}$
Fig. 8 The difference in sound power insulation $\Delta D_{W}$ for the walls of the skeleton enclosure with and without $15 \mathrm{~mm}$ foam, made of aluminium AL2, plywood PW6 and composite ALPO4 (aluminium $0.3 \mathrm{~mm}+$ polyethylene $3.4 \mathrm{~mm}+$ aluminium $0.3 \mathrm{~mm}$ )

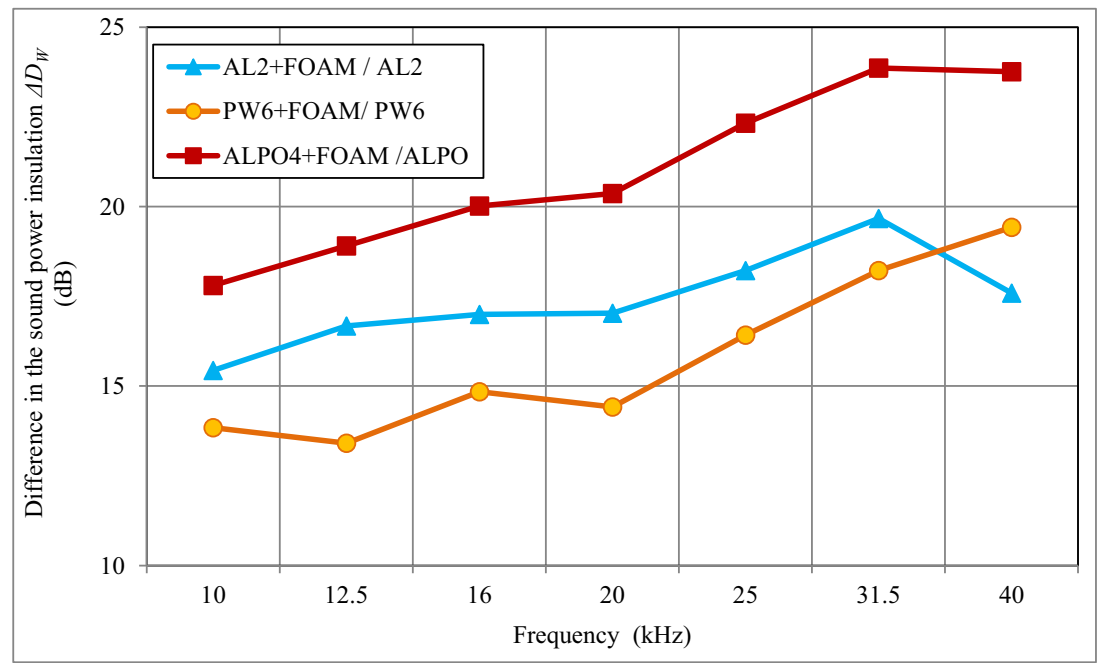


(15.4-19.7 dB) for $2 \mathrm{~mm}$ thick aluminium walls (AL2); $15.8 \mathrm{~dB}(13.4-19.4 \mathrm{~dB})$ for $6 \mathrm{~mm}$ thick plywood walls (PW6); and $21.0 \mathrm{~dB}(17.8-23.9 \mathrm{~dB})$ for $4 \mathrm{~mm}$ thick composite walls (ALPO4).

To recapitulate, the average sound power insulation $D_{W}$ of the skeleton acoustic enclosure made of sheet aluminium with $2 \mathrm{~mm}$ thick walls (AL2) in the frequency range of $10-40 \mathrm{kHz}$ was $32.4 \mathrm{~dB}$ (with $15 \mathrm{~mm}$ foam, it increased by an additional $17.4 \mathrm{~dB}$ ); for plywood enclosure with $6 \mathrm{~mm}$ thick walls (PW6) it was $33.5 \mathrm{~dB}$ (with $15 \mathrm{~mm}$ foam, it increased further by $15.8 \mathrm{~dB}$ ); and for composite enclosure with $4 \mathrm{~mm}$ thick walls (ALPO4) it was $29.6 \mathrm{~dB}$ (with $15 \mathrm{~mm}$ foam lining, it increased by another $21.0 \mathrm{~dB}$ ).

\section{Conclusion}

Enclosures for noise sources emitting the sound energy in the frequency range of $10-40 \mathrm{kHz}$ constitute an effective measure of noise reduction. Leak-proof (in other words, fully closed or sealed) enclosures, without the sound-absorbing material inside, reduce the sound pressure level in the environment (expressed as the sound insulation of acoustic enclosures) by from about $19-27 \mathrm{~dB}$ (for the frequency of $10 \mathrm{kHz}$ ) to about $40-48 \mathrm{~dB}$ (for the frequency of $40 \mathrm{kHz}$ ).

Among the tested enclosures without the sound-absorbing material inside (with $2 \mathrm{~mm}$ thick sheet aluminum walls, $2 \mathrm{~mm}$ thick sheet steel walls, $5 \mathrm{~mm}$ thick plexiglass walls, $5 \mathrm{~mm}$ thick polycarbonate walls, and $4 \mathrm{~mm}$ thick aluminumpolyethylene composite walls), the highest sound insulation of acoustic enclosures, ranging from $27 \mathrm{~dB}$ to $48 \mathrm{~dB}$ for the frequency of $10 \mathrm{kHz}$ and $40 \mathrm{kHz}$, respectively, was observed for the steel acoustic enclosure, whereas the lowest insulation values $(21-40 \mathrm{~dB})$ were obtained for the composite acoustic enclosure.

The sound insulation of acoustic enclosures increased with increasing frequency by $10-12 \mathrm{~dB}$ per octave and with increasing wall thickness by about 5-7 dB per doubled mass.

Applying a sound-absorbing material covering acoustic enclosure walls on the inside results in a significant increase in the sound insulation. It can be estimated that in the tested cases, the resultant average, within the frequency range of $10-40 \mathrm{kHz}$, of the value of sound insulation of the skeleton enclosure made of $2 \mathrm{~mm}$ thick sheet aluminium was $32.4 \mathrm{~dB}$ without and $49.8 \mathrm{~dB}$ with the sound-absorbing material inside; for the acoustic enclosure made of plywood with $6 \mathrm{~mm}$ thick walls 33.5 and $49.3 \mathrm{~dB}$, respectively; and for the acoustic enclosure made of $4 \mathrm{~mm}$ thick composite $-29.6 \mathrm{~dB}$ and $50.6 \mathrm{~dB}$, respectively. To generalise the above results it can be stated that the use of sound-absorbing material inside an acoustic enclosure results in a $32-$
$41 \%$ increase in the sound power insulation of the enclosure. This evidences the vital importance of using sound-absorbing materials inside enclosures for ultrasonic noise sources (emitting sound in the frequency range of $10-40 \mathrm{kHz})$.

The described research results allow to select materials from which sound-insulating enclosures for ultrasonic noise emitting devices are to be made. The results can be also used to estimate the ultrasonic noise level reduction achieved at workstations (and thus to predict the risks related to exposure of workers to ultrasonic noise). In case of using sound-insulating enclosures with different dimensions and/or structure and/or made out of materials different from those subjected to testing, it would be necessary to measure the sound insulation of such enclosures. The present study, in the opinion of the author, has an application potential but at the same time, it can be considered an introduction to a more detailed analysis of the possibility to reduce the hazards related to the ultrasonic noise at workstations. In that area, its seems to be appropriate to undertake the future research effort in three specific areas. The first of such research topics would concern ultrasonic devices and include: developing a method for determination of ultrasonic source noise emissions (the sound power level); determining the noise emission for typical ultrasonic noise sources; and undertaking legislative activities in the scope of ultrasonic noise emission of sources (and possibly restrictions for noise emission from such sources, on the analogy of legal instruments applicable to audible noise i.e. in directives 2006/42/EC and 2005/88/EC [22, 23] and international standards EN ISO 3744:2010 and EN ISO 9295:2015 [24, 25]). Another field of research would pertain to soundabsorbing materials and include: establishing a method for determining sound-absorbing properties of materials in the ultrasonic noise frequency range (the sound absorption coefficient); determining properties of soundabsorbing materials used for inner linings of sound insulating enclosures in the ultrasonic noise frequency range; and initiating legislative activities in the scope of sound-absorbing properties of materials in the frequency range $10-40 \mathrm{kHz}$ (on the analogy of regulations currently applicable to the frequency range 100 $5000 \mathrm{~Hz}$ ). The third area of research would concern soundproof barriers and enclosures (for ultrasonic noise sources), and in particular: developing methods for determining insulation properties of sound-insulating enclosures and barriers used for enclosure walls in the ultrasonic noise frequency range (the sound insulation); determining acoustic insulation properties of soundinsulating enclosures and barriers in the ultrasonic noise frequency range; and entering into legislative activities 
in scope of manufacturers' declarations concerning sound insulation properties of enclosures and barriers in the ultrasonic noise frequency range (on the analogy of EN ISO 11546-2:2009 and EN ISO 15667:2000 [18, 19] currently applicable to lower frequencies).

Acknowledgements This paper is based on results of a research task carried out within the scope of the fourth stage of the National Programme "Improvement of safety and working conditions" partly supported in 2017-2019 — within the scope of state-contracted services by the Ministry of Family, Labour and Social Policy. The Central Institute for Labour Protection-National Research Institute is the Programme's main co-ordinator.

The author thanks the technician Mr. Jerzy Kozłowski for his assistance in taking measurements.

\section{Authors' contributions Not applicable.}

Funding This paper is based on results of a research task carried out as part of the fourth stage of the National Programme "Improvement of safety and working conditions" partly supported in 2017-2019 — within the scope of state-contracted services - by the Ministry of Family, Labour, and Social Policy. The Central Institute for Labour Protection National Research Institute is the Programme's main co-ordinator.

Data availability Not applicable.

\section{Compliance with ethical standards}

Conflicts of interest/competing interests The author declares that he has no conflict of interest.

Code availability Not applicable.

Open Access This article is licensed under a Creative Commons Attribution 4.0 International License, which permits use, sharing, adaptation, distribution and reproduction in any medium or format, as long as you give appropriate credit to the original author(s) and the source, provide a link to the Creative Commons licence, and indicate if changes were made. The images or other third party material in this article are included in the article's Creative Commons licence, unless indicated otherwise in a credit line to the material. If material is not included in the article's Creative Commons licence and your intended use is not permitted by statutory regulation or exceeds the permitted use, you will need to obtain permission directly from the copyright holder. To view a copy of this licence, visit http://creativecommons.org/licenses/by/4.0/.

\section{References}

1. European directive $2003 / 10 / \mathrm{EC}$ on the minimum health and safety requirements regarding the exposure of workers to the risks arising from physical agents (noise). 2003.

2. The Regulation of the Minister of Family, Labour and Social Policy in Poland of 12 June 2018 (Journal of Laws of 2018, item 1286 of 3 July 2018) on Maximum Permissible Concentration and Intensity of Agents Harmful to Health in the Working Environment. 2018; http://prawo.sejm.gov.pl/isap.nsf/DocDetails.xsp?id= WDU20180001286. .
3. Pleban D. Admissible values and methods of measurement of noise, ultrasonic noise and infrasonic noise at workplaces in Poland, conference $23^{\text {rd }}$ international congress on acoustics, 9-13. Aachen, Germany. September 2019:2019 https://publications.rwth-aachen. de/record/767416. .

4. Occupational Safety and Health Administration United States Department of Labor. 2020; https://www.osha.gov/dts/osta/otm/ new noise/. .

5. Lawton BW. Damage to human hearing by airborne sound of very high frequency or ultrasonic frequency, London. Health \& Safety Executive, 77pp. 2001. https://eprints.soton.ac.uk/10750/. .

6. Smagowska B. Ultrasonic noise sources in the work environment. Archives of Acoustics. 2013;38(2):169-76. https://doi.org/10. 2478/aoa-2013-0019.

7. Radosz J, Pleban D. Ultrasonic noise measurements in the work environment. J Acoust Soc Am. 2018;144(4):2532-8. https://doi. org/10.1121/1.5063812 .

8. Radosz J. Methodology issues of ultrasonic noise exposure assessment. Noise Control Engineering Journal. 2012;60(6):645-54 https://www.researchgate.net/publication/271239386 Methodlolgy_issues_of_ultrasonic_noise_exposure_assessment

9. Mikulski W (2017) Method for determination of sound power levels of noise sources in the frequency range above $10 \mathrm{kHz}$, Conference XLV Szkoła Zimowa Akustyki Środowiska $i$ Wibroakustyki, Poland, Szczyrk, 27.02-3.3.2017

10. Mikulski W, Radosz J (2009) Method for determination of sound power levels of ultrasonic noise sources. Determining criteria for specifying the minimum number of measuring points, Conference 56 Otwarte Seminarium Akustyki, 15-18.09.2009. Poland, Warszawa-Goniadz, 2009.

11. Mikulski W. The effect of the application sound-absorbing material inside enclosure on the sound insulation of enclosure in the frequency range $10-40 \mathrm{kHz}$, Conference Noise Control 2019, 2629.05.2019. Poland, Warszawa-Janów Podlaski; 2019.

12. Mikulski W. Method of determining the sound absorbing coefficient of materials within the frequency range of $5000-50000 \mathrm{~Hz}$ in a test chamber of a volume of about $2 \mathrm{~m}^{3}$. Archives of Acoustics. 2013;38(2):177-83. https://doi.org/10.2478/aoa-2013-0020.

13. Pleban D. Method of testing of sound absorption properties of materials intended for ultrasonic noise protection. Archives of Acoustics. 2013;38(2):191-5 https://acoustics.ippt.pan.pl/index. php/aa/article/view/32.

14. Mikulski W (2018) Laboratory sound source operating in frequency range 8-50 kHz, Conference XLVI Szkoła Zimowa Akustyki Środowiska i Wibroakustyki, 26.02-2.3.2018. Poland, Szczyrk, 2018.

15. EN ISO 11690-2:1996. Acoustics - Recommended practice for the design of low-noise workplaces containing machinery - Part 2: Noise control measures. 1996.

16. ASTM E596-96. Standard test method for laboratory measurement of noise reduction of sound-isolating enclosures 2016.

17. E1704-95. Standard guide for specifying acoustical performance of sound-isolating enclosures. 2018.

18. EN ISO 11546-2:2009. Acoustics. Determination of sound insulation performances of enclosures. Part 2: Measurements in situ (for acceptance and verification purposes). 2009.

19. EN ISO 15667:2000. Acoustics. Guidelines for noise control using enclosures and cabins.

20. Dobrucki A, Żółtogórski B, Pruchnicki P, Bolejko R. Soundabsorbing and insulating enclosures for ultrasonic noise. Archives of Acoustics. 2010;35(2):157-64 https://acoustics.ippt.pan.pl/ index.php/aa/article/view/240.

21. Pleban D, Mikulski W. Methods of testing of sound insulation properties of barriers intended for high frequency noise and ultrasonic noise protection. Journal of Mechanical Engineering - 
Strojnicky casopis. 2018;68(4):55-64. https://doi.org/10.2478/ scjme-2018-0047 Accessed 23 June 2020.

22. European directive 2006/42/EC New machinery directive. 2006.

23. European directive 2005/88/EC The noise emission in the environment by equipment for use outdoors. 2005.

24. EN ISO 3744:2010. Acoustics. Determination of sound power levels and sound energy levels of noise sources using sound pressure. Engineering methods for an essentially free field over a reflecting plane. 2010.

25. EN ISO 9295:2015. Acoustics. Determination of high-frequency sound power levels emitted by machinery and equipment. 2015.

26. European directive 2000/14/EC on the approximation of the laws of the Member States relating to the noise emission in the environment by equipment for use outdoors. 2000.

27. Śliwiński A. Assessment of ultrasonic noise hazard in work places environment. Archives of Acoustics. 2013;38(2):243-52. https:// doi.org/10.2478/aoa-2013-0029 .

28. Śliwiński A. On the noise hazard assessment within the intermediate range of the high audible and the low ultrasonic frequencies.
Archives of Acoustics. 2016;41(2):331-8. https://doi.org/10.1515/ aoa-2016-0034 .

29. Kling C, Koch C, Kühler R (2015) Measurement and assessment of airborne ultrasound noise, Proceedings The 22nd International Congress on Sound and Vibration, Italy, 12-16.07.2015. 2015. $\mathrm{http} / / /$ www.life-dynamap.eu/the-22nd-international-congress-onsound-and-vibration-icsv22/. .

30. Pleban D (editor) (2020) Occupational noise and workplace acoustics: advances in measurement and assessment techniques. Chapter: Studies on sound insulation of enclosures in the $10-40 \mathrm{kHz}$ frequency range, by Mikulski W., Taylor \& Francis Group, Boca Raton, CRC Press, p. 253-274. https://doi.org/10.1201/ 9781003048121.

Publisher's note Springer Nature remains neutral with regard to jurisdictional claims in published maps and institutional affiliations. 